\title{
ENHANCED PROPERTIES FROM MIXING NATURAL RUBBER WITH RECYCLED POLYVINYL CHLORIDE BY MELT BLENDING
}

\author{
H. Norazlina ${ }^{1 *}$, R.M. Firdaus ${ }^{1}$ and W.M. Hafizuddin ${ }^{1}$ \\ ${ }^{1}$ Faculty of Chemical Engineering Technology, TATI University College, \\ Jln Panchor, Teluk Kalong, 24000, Kemaman, Terengganu, Malaysia \\ *Email: norazlina@tatiuc.edu.my \\ Phone: +6098601000; Fax: +6098635863
}

\begin{abstract}
The growing consumption of polymer products has created large quantities of waste materials resulting in environmental issues. Researchers have started to focus on recycling materials, not only for environmental reasons but also to decrease the cost. Polyvinyl chloride (PVC) is a universal non-biodegradable polymer which can be processed into a variety of long-life and short-life products. Blending with biodegradable natural rubber is a nice combination to convert composites into biodegradable products. In this study, natural rubber/recycled PVC composites, with different percentage loadings of each material, were produced using a two-roll mill to ascertain the optimum properties of the blends by analyzing the mechanical and thermal properties. The hardness and the modulus were enhanced with the increasing r-PVC loading. The elongation at break increased with the r-PVC loading but decreased dramatically after $40 \%$ r-PVC loading while the tensile strength decreased after the $60 \%$ r-PVC loading. In the thermal analysis, the crystallization temperature and melting point increased with the r-PVC loading.
\end{abstract}

Keywords: Natural rubber; recycled PVC; mechanical properties; thermal properties.

\section{INTRODUCTION}

Natural rubber (NR) is an elastomer produced from the latex of the rubber tree. NR, as a natural renewable resource, has many excellent comprehensive properties, such as outstanding resilience, high strength and good processability [1-3]. However, as an unsaturated polymer, NR tends to gradually degrade at higher temperatures or when exposed to oxygen, ozone or ultraviolet, which has a significant negative effect on its special applications [4-7]. Its low mechanical properties, with low surface energy and low barrier properties, are one of the reasons NR must be blended with other materials to enhance the properties [8-11]. Unfortunately, there is a lack of research focusing on blending NR with recycled materials. A review by Huang et al. [12] into the application of solid waste material (SWM) in the UK for asphalt pavements provides an overview on recycling materials. They covered the waste from glass, steel slag, scrap tires and plastics. Tire rubber is used in asphalt mixtures to reduce cracking, improve durability and mitigate noise. Recycled plastics can either replace a portion of the aggregates or serve as a binder modifier, such as for low density polyethylene (LDPE) which is replacing $30 \%$ of the $2.36-5 \mathrm{~mm}$ aggregates, reduces the mix density by $16 \%$, shows a $250 \%$ increase in Marshall Stability and improves the indirect tensile strength (ITS) in 'Plastiphalt' mixtures [13]. Recycled $0.30-0.92-\mathrm{mm}$ size LDPE, replacing $15 \%$ of the 
aggregates in asphalt surfacing, has increased the stability retained (SR) by $15 \%$, and enhanced the rutting and water resistance. Recycled PVC bottles contribute to increasing the bending strength by adding $2-6 \%$ of the mixture by weight. Recycled polyethylene (PE) film is used for $0.4 \%$ of the mixture by weight (about $8 \%$ of the binder weight) as a bitumen modifier, increasing the Marshall Stability before and after logging.

PVC is one of the most commonly used thermoplastic materials in worldwide polymers. Because of the particular properties of PVC, such as its low cost and high performance, and the high possibility of producing a variety of products from different processing conditions and techniques, PVC has becomes the polymer of choice [14-18]. Recently, the question of the disposal of PVC waste resulting from its rapid growth has resulted in increased public awareness. One of the simple routes for disposing of PVC waste is landfill but it has become more expensive and, in many countries, this method of disposal in no longer approved due to increasing consumption, the lack of landfill areas, and the environmental hazards associated with the chlorine content of the polymer [19-22]. A more suitable route without environmental problems, and in combination with recovering the polymer energy and material content, is recycling. Until now, researchers and industrialists have been funded in this field. They have proposed that PVC can be successfully recycled into several products, such as bottles, pipes, and pipe fittings among others, with good appearance and properties. PVC is now one of the largest recycled polymers by volume in developed countries as it has attracted attention in the fields of research and technology.
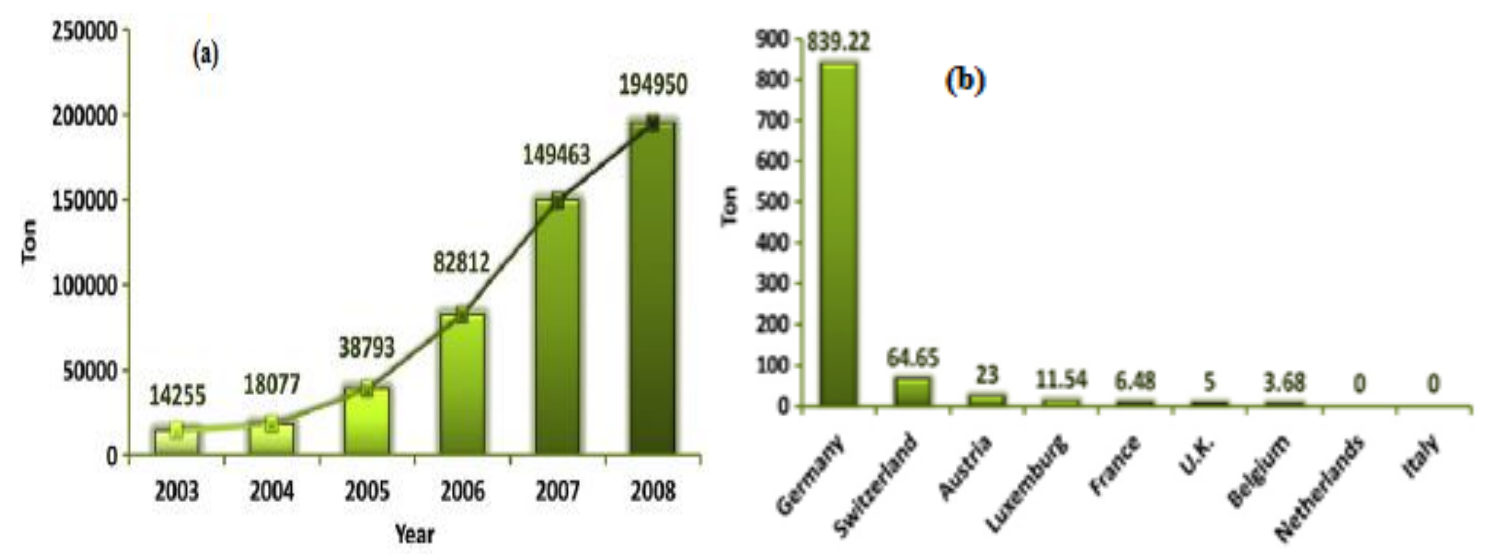

Figure 1. (a) The tonnage of recycled PVC in Europe from 2003 until 2008; (b) The tonnage of roofing materials recycled in Europe by country in 2008 [16].

Although recycling has taken place, it should be stressed here that many plastics cannot simply be separated or processed. Moreover, the mixed recycled material would have poor mechanical properties compared to the original material and only a narrow range of possible applications. Currently, the recycling operations for polymers, PVC in particular, are increasing, especially in the following aspects: development of techniques and instrumentation for the separation of PVC from waste streams, improvement of the current methods or development of new methods, research into the compatibility of recycled PVC with other polymers and virgin PVC, recycling of mixed PVC waste and enhancement of the physical and mechanical properties of recycled PVC [16]. This study aims to justify the mechanical properties of unfilled NR and 
NR/recycled PVC (NR/r-PVC) blends. The thermal properties of all samples will also be analyzed. The main purpose of this study is to reduce PVC waste and convert it into more valuable materials. The second rationale is due to the fire resistant behavior of PVC after that of polytetrafluoroethylene (PTFE) [23]. This superiority meets the shortage of NR which is easily burned. The oxygen index is used to evaluate the fire retardant properties of plastic. Table 1 shows the comparison of the oxygen index between PVC and other polymers: PTFE, polycarbonate [24], polyethylene terephthalate (PET), polystyrene (PS), polypropylene (PP) and polyethylene (PE). Since the oxygen concentration in the air is $21 \%$, a plastic with an oxygen index greater than 22 is classified as a self-extinguishing property, while a plastic with an oxygen index of less than 21 is flammable.

Table 1. The oxygen index of various plastics [23].

\begin{tabular}{ccccccc}
\hline Materials & PTFE & PVC & PC & PET & PS & PP PE \\
\hline Oxygen Index & 95.0 & $45 \sim 49$ & $26 \sim 28$ & 20.0 & $17.6 \sim 18.3$ & 17.417 .4 \\
\hline
\end{tabular}

\section{Experimental Procedure}

Standard Malaysia Rubber 10 (SMR-10) NR was supplied by Lee Rubber Sdn. Bhd., Kelantan and recycled PVC was obtained from PVC matting. Other materials were obtained commercially. Three major steps were involved: preparation of the samples, mixing and characterization.

\section{Preparation of Samples}

The recycled PVC (r-PVC), obtained from recycled PVC matting, was washed with distilled water and dried in an oven overnight. Then, the material was blended using an IKA basic analytical mill in order to grind it. The blended r-PVC was sieved using a $112-\mu \mathrm{m}$ sized sieve.

\section{Mixing Process}

Five samples were prepared with different NR and recycled PVC loadings (by weight percentage, wt.\%): $100 \mathrm{NR}, 80 / 20 \mathrm{NR} / \mathrm{r}-\mathrm{PVC}, 60 / 40 \mathrm{NR} / \mathrm{r}-\mathrm{PVC}, 40 / 60 \mathrm{NR} / \mathrm{r}-\mathrm{PVC}$ and 20/80 NR/r-PVC as shown in Table 2. The samples were compounded via melt blending using a two-roll mill at $35-40{ }^{\circ} \mathrm{C}$ and four chemicals of fixed amounts were added continuously during mixing to assist in acceleration and crosslinking. Initially, the NR was masticated on the mill for $15 \mathrm{~min}$. Thereafter, the rubber was blended with zinc oxide, stearic acid, CBS, r-PVC and sulfur. The mixture was plasticized for 10-15 min and thin-passed several times at $70-80{ }^{\circ} \mathrm{C}$. For higher r-PVC loadings (60\% and above), the r-PVC became a matrix and the NR was a filler. First, the r-PVC was melted with a melting point of around $160{ }^{\circ} \mathrm{C}$, followed by the addition of zinc oxide, stearic acid, CBS, NR and sulfur. At this stage, the temperature was decreased to around $70-80{ }^{\circ} \mathrm{C}$. Last, the obtained samples were hot-pressed using a 1-mm thick mold to form sheet samples. 
Table 2. The composition of the samples.

\begin{tabular}{ll}
\hline $\begin{array}{l}\text { Sample, } \\
\text { NR/r-PVC }\end{array}$ & Chemical compositions added to \\
\hline 100 & all samples $(\%)$ \\
$80 / 20$ & Zinc oxide $(5 \%) ;$ stearic acid $(2 \%) ;$ \\
$60 / 40$ & cyclohexylbenzothiazole- \\
$40 / 60$ & sulfenamide $(\mathrm{CBS})(2.5 \%) ;$ sulfur \\
$20 / 80$ & $(0.5 \%)$ \\
\hline
\end{tabular}

\section{Characterization Process}

All five prepared samples were tested using Shore durometer hardness testing in accordance with ASTM D2240 [25] to measure the resilient material's resistance to indentation. Each sample was tested three times for measurement accuracy. During the hardness testing, the sample was put on a flat surface. The Shore durometer hardness tester was pressed onto the sample. After 15 seconds, the reading was shown by durometer. Tensile testing measures the force required to break a plastic sample and the extent to which the sample stretches or elongates to that breaking point. The samples were cut into dumbbell shapes using the ASTM D412 standard cutter. The tensile test was undertaken using an Instron Universal Testing Machine. Thermal analysis was undertaken using differential scanning calorimetry (DSC) employing a Mettler Toledo to determine the temperature of a sample to glass transition $\left(T_{g}\right)$, crystallization temperature $\left(T_{c}\right)$ and melting point $\left(T_{m}\right)$. During DSC characterization, the weighed sample was put in an aluminum pan clamped using the clamp pan in the DSC equipment and the experiment was run at temperatures in the range $-80{ }^{\circ} \mathrm{C}$ to $500{ }^{\circ} \mathrm{C}$ at a heating rate $10{ }^{\circ} \mathrm{C} / \mathrm{min}$.

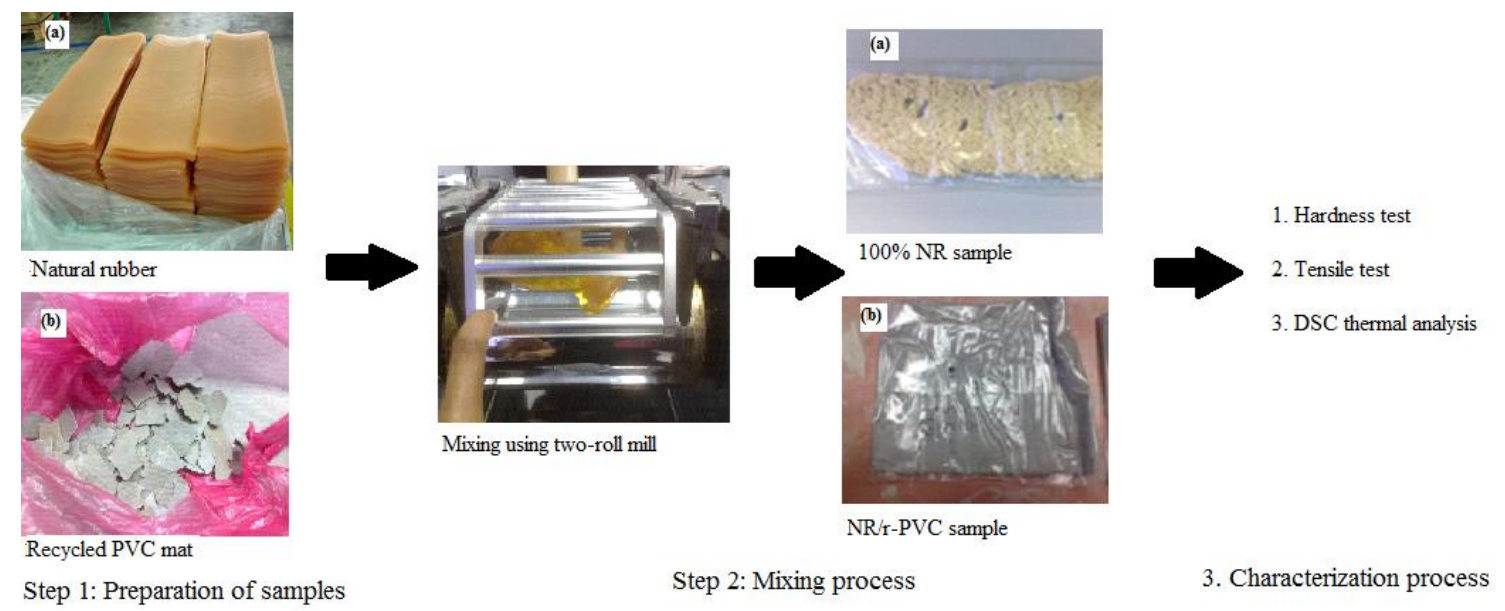

Figure 2. Schematic diagram of the preparation of the samples, mixing using a two-roll mill and characterization. 


\section{RESULTS AND DISCUSSION}

\section{Mechanical Properties of Samples}

The mechanical properties of the unfilled NR and NR/r-PVC blends are presented in Table 3. The hardness and the modulus were enhanced with the increased r-PVC loading. The incorporation of r-PVC into the rubber matrix increased the stiffness of the vulcanizates, given that the tensile modulus represents the material stiffness [1]. The reinforcement effect of r-PVC, such as hardness, modulus and tensile strength, may be explained by the interaction between the rubber and r-PVC chain. The elongation at break was increased by the r-PVC loading but decreased dramatically after $40 \%$ r-PVC. The tensile strength also showed a decrease after $60 \%$ r-PVC loading due to the increased aggregation of r-PVC in the matrix. These results showed similar findings to those of other researchers [26]. The increase in tensile strength and elongation at break were caused by the filler particles being fully wetted by the NR matrix, especially at low loading. The rubber chain could penetrate into the pores of the r-PVC filler and become a part of the filler (bound rubber). The further addition of r-PVC as a filler decreased the tensile strength and elongation at break. This was caused by agglomeration in the filler particles, thereafter being less wetted and less penetrated by the NR chains, which had a detrimental effect on the tensile strength and elongation at break [27].

Table 3. Mechanical properties of samples.

\begin{tabular}{ccccc}
\hline $\begin{array}{c}\text { Sample, NR/r- } \\
\text { PVC }(\%)\end{array}$ & $\begin{array}{c}\text { Hardness } \\
\text { (Shore A) }\end{array}$ & $\begin{array}{c}\text { Elongation at } \\
\text { break }(\mathrm{mm})\end{array}$ & $\begin{array}{c}\text { Tensile } \\
\text { strength }(\mathrm{MPa})\end{array}$ & $\begin{array}{c}\text { Tensile } \\
\text { modulus }(\mathrm{MPa})\end{array}$ \\
\hline 100 & 10.8 & 349 & 20 & 1.9 \\
$80 / 20$ & 22.3 & 380 & 24 & 2.0 \\
$60 / 40$ & 32.5 & 153 & 24.5 & 4.7 \\
$40 / 60$ & 49.5 & 87.8 & 20 & 8.6 \\
$20 / 80$ & 33.3 & 17.5 & 18.4 & 8.8 \\
\hline
\end{tabular}

\section{Thermal Analysis of Samples}

DSC measurements were taken for all blends in order to study the influence of both nature and the content of r-PVC on the glass transition temperature of the NR matrix. Compared to the neat NR matrix, no significant variation in $T_{g}$ on the r-PVC addition was reported regardless of the nature and content of the r-PVC [28, 29]. Recycled PVC itself is a polymer and contains plasticizer which is added during the manufacture of PVC matting. The crystallization temperature and melting point increased due to the $\mathrm{r}-$ PVC loading. At $60 \%$ r-PVC loading, the $T_{m}$ increased to $416.20{ }^{\circ} \mathrm{C}$, due to the PVC being highly fire resistant. At the $80 \%$ r-PVC loading, a slight decrease in $T_{c}$ and $T_{m}$ was shown. This can be explained by the aggregation causing the materials to be no longer compatible with each other. The viscosity of the blends increased because of the poor flowability of the neat NR; hence, the diffusion rate of the r-PVC chains was reduced [27]. 
Table 4. DSC analysis results for NR and its blends.

\begin{tabular}{cccc}
\hline $\begin{array}{c}\text { Sample, NR/r- } \\
\text { PVC }(\%)\end{array}$ & $\begin{array}{c}\text { Glass transition, } \\
T_{g}\left({ }^{\circ} \mathrm{C}\right)\end{array}$ & $\begin{array}{c}\text { Crystallization } \\
\text { temperature, } T_{c}\left({ }^{\circ} \mathrm{C}\right)\end{array}$ & $\begin{array}{c}\text { Melting point, } \\
T_{m}\left({ }^{\circ} \mathrm{C}\right)\end{array}$ \\
\hline 100 & -60.98 & 198.08 & 377.08 \\
$80 / 20$ & -61.46 & 266.51 & 340.57 \\
$60 / 40$ & -62.33 & 270.51 & 360.17 \\
$40 / 60$ & -62.03 & 286.84 & 416.20 \\
$20 / 80$ & -63.80 & 272.40 & 333.35 \\
\hline
\end{tabular}

\section{CONCLUSIONS}

Recycling of waste materials is compulsory as a result of global environmental issues caused by the increase in waste over the years. In this study, NR and NR/r-PVC blends were produced by melt compounding and compression molding. The effect of r-PVC loading on the mechanical and thermal properties was studied. This research showed results in parallel with other studies as noted in the discussion. The hardness reached its maximum at $40 / 60 \% \mathrm{NR} / \mathrm{r}-\mathrm{PVC}$ blending, while the tensile strength showed a decreasing trend after $60 \%$ r-PVC loading. The tensile modulus was enhanced due to the r-PVC loading. The glass transition temperature showed no significant variation. Furthermore, both $T_{c}$ and $T_{g}$ gave the highest result for $40 / 60 \%$ NR/r-PVC blending, with a crystallization temperature of $286.84{ }^{\circ} \mathrm{C}$, and a melting point temperature of $416.20{ }^{\circ} \mathrm{C}$.

\section{ACKNOWLEDGEMENTS}

The authors gratefully acknowledge the Faculty of Chemical Engineering Technology, TATI University College for providing laboratory facilities and giving supports in this study.

\section{REFERENCES}

[1] Nabil H, Ismail H. Enhancing the thermal stability of natural rubber/recycled ethylene-propylene-diene rubber blends by means of introducing pre-vulcanised ethylene-propylene-diene rubber and electron beam irradiation. Materials \& Design. 2014;56:1057-67.

[2] Mohamad N, Nur Sharafina Z, Ab Maulod HE, Yuhazri MY, Jeefferie AR. Morphological and mechanical properties of polypropylene/epoxidized natural rubber thermoplastic vulcanizates treated with maleic anhydride-grafted polypropylene. International Journal of Automotive and Mechanical Engineering. 2013;8:1305-15.

[3] Ravi Sankar H, Srikant RR, Vamsi Krishna P, Bhujanga Rao V, Bangaru Babu P. Estimation of the dynamic properties of epoxy glass fabric composites with natural rubber particle inclusions. International Journal of Automotive and Mechanical Engineering. 2013;7:968-80.

[4] Wang ZF, Peng Z, Li SD, Lin H, Zhang KX, She XD, et al. The impact of esterification on the properties of starch/natural rubber composite. Composites Science and Technology. 2009;69:1797-803. 
[5] Zhou M-H, Hoang T, Kim I-G, Ha C-S, Cho W-J. Synthesis and properties of natural rubber modified with stearyl methacrylate and divinylbenzene by graft polymerization. Journal of Applied Polymer Science. 2001;79:2464-70.

[6] Aeyzarq Muhammad Hadzreel MR, Siti Rabiatull Aisha I. Effect of reinforcement alignment on the properties of polymer matrix composite. Journal of Mechanical Engineering and Sciences. 2013;4:548-54.

[7] Khairul Zaimy AGM, Zafiah A, Rus M, Ab Latif N, Nurulsaidatulsyida S. Mechanical and thermal properties of waste bio-polymer compound by hot compression molding technique. Journal of Mechanical Engineering and Sciences. 2013;5:582-91.

[8] Nair AB, Joseph R. Eco-friendly bio composites using natural rubber NR matrices and natural fiber reinforcements. In: Kohjiya S, Ikeda Y, editors. Chemistry Manufacture and Applications of Natural Rubber: Elsevier. 2014; 249-83.

[9] Zhang Y, Liu Q, Zhang Q, Lu Y. Gas barrier properties of natural rubber/kaolin composites prepared by melt blending. Applied Clay Science. 2010;50:255-9.

[10] Nakason C, Saiwaree S, Tatun S, Kaesaman A. Rheological, thermal and morphological properties of maleated natural rubber and its reactive blending with poly(methyl methacrylate). Polymer Testing. 2006;25:656-67.

[11] Mei GS, Yuvaraj AR, Kabeb SMb, Yusoff MM, Chigrinov VG, Hegde G. Biocompatible Polymer Embedded in Light-Sensitive Materials: Investigation of Structural Properties. International Journal of Automotive and Mechanical Engineering. 2014;10:2025-33.

[12] Huang Y, Bird RN, Heidrich O. A review of the use of recycled solid waste materials in asphalt pavements. Resources, Conservation and Recycling. 2007;52:58-73.

[13] Zoorob SE, Suparma LB. Laboratory design and investigation of the properties of continuously graded Asphaltic concrete containing recycled plastics aggregate replacement (Plastiphalt). Cement and Concrete Composites. 2000;22:233-42.

[14] Garcia D, Balart R, Crespo JE, Lopez J. Mechanical properties of recycled PVC blends with styrenic polymers. Journal of Applied Polymer Science. 2006;101:2464-71.

[15] Yarahmadi N, Jakubowicz I, Martinsson L. PVC floorings as post-consumer products for mechanical recycling and energy recovery. Polymer Degradation and Stability. 2003;79:439-48.

[16] Sadat-Shojai M, Bakhshandeh G-R. Recycling of PVC wastes. Polymer Degradation and Stability. 2011;96:404-15.

[17] Hamdan S, Kiew KS, Rahman MR. Dielectric Properties of Maleic Anhydride Modified Unsaturated Polyester Composites Reinforced with Chicken Feather Fibre. International Journal of Automotive and Mechanical Engineering. 2014;10:1971-9.

[18] Then YY, Ibrahim NA, Zainuddin N, Ariffin H, Wan Yunus WMZ, Abd Rahman MF. Effect of electron beam irradiation on the tensile properties of oil palm mesocarp fibre/poly(Butylene Succinate) biocomposites. International Journal of Automotive and Mechanical Engineering. 2014;10:2070-80.

[19] Garcia D, Balart R, Sanchez L, Lopez J. Compatibility of recycled PVC/ABS blends. Effect of previous degradation. Polymer engineering and science. 2007;47:789. 
[20] Ditta AS, Wilkinson AJ, McNally GM, Murphy WR. A study of the processing characteristics and mechanical properties of multiple recycled rigid PVC. Journal of Vinyl and Additive Technology. 2004;10:174-8.

[21] Hardinnawirda K, SitiRabiatull Aisha I. Effect of rice husks as filler in polymer matrix composites. Journal of Mechanical Engineering and Sciences. 2012;2:181-6.

[22] Ab Latif N, M. Rus AZ. Vibration transmissibility study of high density solid waste biopolymer foam. Journal of Mechanical Engineering and Sciences. 2014;6:772-81.

[23] Sevenster A. Fire retarding properties. PVC: PVC Europe.

[24] Usta N, Öztürk E, Can Ö, Conkur E, Nas S, Con A, et al. Combustion of biodiesel fuel produced from hazelnut soapstock/waste sunflower oil mixture in a diesel engine. Energy Conversion and Management. 2005;46:741-55.

[25] Testing ASf, Materials. Standard Test Method for Rubber Property--Durometer Hardness. ASTM; 2005.

[26] Nabil H, Ismail H, Azura AR. Compounding, mechanical and morphological properties of carbon-black-filled natural rubber/recycled ethylene-propylenediene-monomer (NR/R-EPDM) blends. Polymer Testing. 2013;32:385-93.

[27] Lei Y, Wu Q, Yao F, Xu Y. Preparation and properties of recycled HDPE/natural fiber composites. Composites Part A: Applied Science and Manufacturing. 2007;38:1664-74.

[28] Bendahou A, Kaddami H, Dufresne A. Investigation on the effect of cellulosic nanoparticles' morphology on the properties of natural rubber based nanocomposites. European Polymer Journal. 2010;46:609-20.

[29] Fragiadakis D, Bokobza L, Pissis P. Dynamics near the filler surface in natural rubber-silica nanocomposites. Polymer. 2011;52:3175-82. 